\title{
Health Demand in Indonesia: Health Stock Approach
}

\author{
Mohamad Ichwan ${ }^{1, *}$, Haerul Anam ${ }^{1}$, Samuel Y. Sir ${ }^{1}$, Sudarkam R. Mertosono², Rita Yunus ${ }^{1}$ \\ ${ }^{1}$ Faculty of Economics and Business, Universitas Tadulako, Indonesia \\ ${ }^{2}$ Faculty of Teacher Training and Education, Universitas Tadulako, Indonesia
}

Received June 18, 2021; Revised August 25, 2021; Accepted September 21, 2021

\section{Cite This Paper in the following Citation Styles}

(a): [1] Mohamad Ichwan, Haerul Anam, Samuel Y. Sir, Sudarkam R. Mertosono, Rita Yunus, "Health Demand in Indonesia: Health Stock Approach," Universal Journal of Educational Research, Universal Journal of Public Health, Vol. 9, No. 5, pp. 268 - 275, 2021. DOI: 10.13189/ujph.2021.090509.

(b): Mohamad Ichwan, Haerul Anam, Samuel Y. Sir, Sudarkam R. Mertosono, Rita Yunus (2021). Health Demand in Indonesia: Health Stock Approach. Universal Journal of Public Health, 9(5), 268 - 275. DOI: 10.13189/ujph.2021.090509.

Copyright $\odot 2021$ by authors, all rights reserved. Authors agree that this article remains permanently open access under the terms of the Creative Commons Attribution License 4.0 International License

\begin{abstract}
Health demand of Grossman Model recognizes three determinant factors in estimation model such as wage, education, and age. This study intends to examine the role of wage on health demand using measurement of total sick days and that of health days as measurement for health demand applying Econometrics Model in the form of Ordinary Least Squares (OLS) Technique. It employed household data from National Social Economy Survey Panel containing reports on the two areas examined among respondents in urban area. We found that the number of respondents who were ill was 6.642 and those who were not was 9.895 . We also found that increase on wage reduced sick day total among working class families but not for middle class families, and it also triggered health time for both middle-working class families. Low Elasticity Coefficient indicated inelastic health demand which needs one-fold wage increase to improve one percent of health demand. Such inelasticity in demand can increase the price of medical services in long term and is potential for health stock disparity for the people. To avoid this, health insurance is needed to cover the people in order to improve health time of the people.
\end{abstract}

Keywords Health Demand, Wage, Grossman Model, Sick Day, Health Time, Health Stock and Health Insurance

\section{Background}

Physical and cognitive improvement for the people indicates the important role of health in economy growth in order to be able to use better production technology. Mills et al., [1] stated that the increase of labor productivity directly impacts on labor and on fertility, mortality, and intellectuality $[2,3]$. Attention toward demand side needs to be triggered in order to uncover health role in economic development $[4,5]$.

In the period of 1997-2009 in Indonesia, health expense per capita tended to increase followed by the proportion of people who looked for traditional medicine exceeded increase in the proportion of people who suffered from sickness. This has pushed the people to believe that traditional medicine is an alternative for health care and an indication of health demand issue [6].

In Indonesian society, traditional medicine plays an important role in healing solution [6]. It is regarded as a substitute detected in the decrease of government medical utility, although among other groups, it is a complementary good. In understanding health demand model in Indonesia, which involves traditional medicine, it is expected to improve estimation model for health demand.

\section{Literature Review}

Becker's [7] Household Production Theory triggered by Grossman's [8] Health Demand Model is of leaning on health investment $[9,10,11]$. Investment has triggered health demand in the utility function, health stock change, and health depreciation (when age increases). Health is improved through health investment although, at the same time, health depreciation happens [12]. Grossman model 
adds on neoclassic understanding marked with similarity between marginal utility and cost of health investment [9, 10, 11, 13, 14]. Time, according to Grossman [8], is a limited resource -24 hours a day for 365 days a year, or 8.760 hours a year-optimally used for varied activities. This is in line with Abdul-Rahman [15] who also mentioned time constraint as highlighted by Grossman [8] in his model that "... the time constraint property..., limiting time use to major activities such as working time, time use in health production, time use in non-health production, and sick time." Health status, according to Santerre \& Neun [16], is determined by health endowment, life styles such as diet and exercises, social and economic status such as education and poverty, and environment such as quality of water and air.

Most of the research findings on health demand of Grossman Model support the three hypotheses of the study. First, wage positively influences health demand. Second, health depreciation negatively affects health demand. Third, education level positively impacts health demand. Grossman [ㅇ] and Geda \& Simeles [17] found that age positively affect health demand as the hypothesis suggest, some research findings such as Khanam et al., [18]; Gerdtham \& Johannesson [19]; Gerdtham et al., [20]; Vork [21]; Zhao [22] discovered that age does affects, while Wagstaff [23]; Shehzad [24]; Abdul-Rahman [15]; Pandey [25] discovered that age affects health demand but insignificant.

Wage increase will boost health input consumption such as medical care and activities encouraging health stock. Healthy people get more advantages from health improvement in form of wage increase received. Some research findings used wage and income interchangeably in estimation model. Grossman [26] investigated the effect of wage using negative elasticity income of health day. Wage is prioritized because it is able to describe the actual purchasing power parity, which is eventually labeled as income due to data shortage. Other researchers, such as Wagstaff [23]; Shehzad [24]; Gerdtham \& Johannesson [19]; Gerdtham et al., [20]; and Vork [21], used income as wage proxy and supported wage influence. By using per capita expense as wage proxy, Geda \& Simeles [17] found positive influence of wage upon health in urban area, while Zhao [22] and Abdul-Rahman [15] consistently using wage in empirical model found mark as expected although it is insignificant.

Several research scrutinizing the effect of income on medical care demand found different results. Wagstaff [23]; Abdul-Rahman [15]; and Vork [21] supported the hypothesis of income, while Nocera \& Zweifel [27] found insignificant positive impact. Mocan et al., [28] using elasticity to measure the effect of income and price on medical care demand found a connection between income and medical care demand.

Education functions as technology in health production process. It encourages efficiency in health production by improving productivity of marginal input of health - better education positively replaces health stock. Such an impact is proven by some researchers including Grossman [8]; Grossman [26]; Grossman [29]; Grossman [30]; Wagstaff [23]; Gerdtham \& Johannesson [19]; Gerdtham et al., [20]; Vork [21]; Shehzad [24]; Zhao [22]; Abdul-Rahman [15]; Aranda [31]. Even though Pandey [25] finding is not significant, education role remains consistently positive. Furthermore, Khanam et al., [18] reported that effect of education is different between genders of parents, which specifically proved that parents' education really afflicted health demand of children in different direction, that is mother's positively influences while father's does negatively. Such a finding is in favor of the belief that education influences health, but no reason was detected for the negative influence of father's education.

Empirical discrepancies of age, wage, and education toward research on health demand occur due to difference in estimation model and health measurement. Some researchers, such as Grossman [26]; Wagstaff [23]; Vork [21]; Zhao [22]; Shehzad [24]; Pandey [25] employed single measurement in the form of Self-reported Health Status Model, and others like Gerdtham \& Johannesson [19] and Gerdtham et al., [20] made use of Rating Scale, Time Trade-off Health, and Self-rated Health Condition. For medical care demand, Grossman [26] employed actual dollar total spent for medical care, while Nocera \& Zweifel [27] used annual gross expenses.

This study was carried out based on three main components of Grossman model, which included health depreciation, gross investment, and cost investment. Aranda [31] has developed health depreciation by integrating morbidity, which took into account that health depreciation would not occur solely because of age, but other factor, i.e., bad life behavior, was considered to cause illness. Abdul-Rahman [15] has developed time for health, which concerned with physical activities. He believes that physical activities were parts of time input used for health in addition to time for medical purposes. People cultivated their rationales to use time to take care of health through minimizing health cost. According to Abdul-Rahman [15], physical activities are needed to promote fitness. Certain exercises with controlled duration help to improve health for those who suffer from particular illness. Thus, time for physical activities can promote decision for health investment.

The study intends to look at the role of wage in health demand estimation model of urban area in Indonesia. Similar research previously done in the topic concerned, for example Grossman [8]; Wagstaff [13]; Wagstaff [23]; Gerdtham \& Johannesson [19]; Nocera \& Zweifel [27]; Gerdtham et al., [20]; and Vork [21], were based on Household Unit Analysis. Similarly, Jacobson [32]; Bolin et al., [33], and Hjortsberg [34] suggested that Household Unit Analysis is appropriate for developing countries due to high family dependency. Thus, this study chose 
household as unit analysis to differentiate the current study from the previous ones.

\section{Data Description and Model Specification}

To understand how wage plays an important role in health demand, we adapted Grossman [8] model and that of Abdul-Rahman [15]. The data of the study were collected from Susenas (National Social Economy Survey) of 71.932 households using Effective Demand Theory-households with health expenses. We recorded 23.341 households with sickness. We also noted that there were 6.642 households with sickness in the urban area and 9.895 households with health time. Thus, the number of sampled households in this study differed between the two health demand measurements.

Using Grossman [8] model, which starts from health demand, health depreciation, and health investment, while also including traditional medicine within health investment Ichwan [35], we adapted Aranda [31] depreciation model as in the following formula.

$$
\ln \delta_{i}=\ln \delta_{0}+\tilde{\delta} i+V(N)
$$

As indicated in the formula, $\mathrm{V}(\mathrm{N})$ represents life style (other than age) affecting health depreciation. In this study, the life styles intended included smoking and exercises. Using least cost equilibrium of health investment, we found another health demand reduction form by adding $(\mathrm{N})$ on $\varepsilon V$ to mark factor other than age also affected health depreciation, such as smoking and exercises as presented below.

$$
\ln H_{i}=\alpha_{i} \varepsilon \ln W_{i}-\alpha_{i} \varepsilon \ln P+r_{H} \varepsilon E-\tilde{\delta} \varepsilon i-\varepsilon \ln \delta_{0}-
$$

Based on the review of the literature, it was indicated that wage, medical price, education, and age were main variables in health demand estimation. Several researchers including Grossman [26]; Wagstaff [23]; Gerdtham \& Johannesson [19]; Vork [21]; Shehzad [24]; Zhao [22]; and Pandey [25] argue that wage positively influence health demand, while Gupta \& Grave [36] reported such an influence was not significant. In this study, we discovered that wage positively affected health demand.

Income positively afflicted health demand. Grossman [8] found that income negatively affects such demand when wage is included as independent variable. Such a finding was probably due to multicolinearity between the two (wage and income) - it was proven that income coefficient became positive when wage was eliminated. Researchers like Wagstaff [23]; Gerdtham \& Johannesson [19]; Gerdtham et al., [20]; Vork [21]; Shehzad [24] supported such effect although other studies by Zhao [22] and Khanam et al., [18] reported this is not significant.

Family size negatively influenced health demand as reported by Grossman [8]; Geda \& Simeles [17], although Shehzad [24] and Zhao [22] found this was not significant. Due to a trade-off relationship between income and family size, and because Grossman [8] reported that per capita income positively affected health demand, this study excluded household per capita income, which has actually been pictured in the wage of family head.

Health demand in this study was determined by wage $(\mathrm{W})$, medical care price $(\mathrm{P})$ which included health insurance (INS), education (E), age (A), smoking (S) and exercises (Ex), and region (R) treated as controlled variable. Investigation on effect of education (E), which consisted of seven levels, was carried out using Chow Test. The formula for health demand was presented below.

$$
\begin{array}{r}
\ln H=\beta_{10}+\beta_{11} \ln W+\beta_{12} I N S+\beta_{13} A+\beta_{14} \ln S+ \\
\beta_{15} \ln E X+u_{1}(3)
\end{array}
$$

The relationship among the controlled variables was illustrated as follows:

$$
\begin{aligned}
\frac{\partial \ln H}{\partial \ln W}=\beta_{11} & >0 ; \frac{\partial \ln H}{\partial I N S}=\beta_{12}>0 ; \frac{\partial \ln H}{\partial A}=\beta_{13} \\
& <0 ; \frac{\partial \ln H}{\partial \ln S}=\beta_{14}<0 ; \frac{\partial \ln H}{\partial \ln E x}=\beta_{15} \\
& >0
\end{aligned}
$$

Demand model in this study was taken from a structural equation. In terms of health demand model, reduction was used to allow estimation through Ordinary Least Squares (OLS). Reduction form of health demand that has been previously introduced in formula (3) has its own variable names and definitions as follows:

$\ln H \quad=$ Health natural logarithm: loss day total and health time total

$\ln W \quad=$ Wage natural logarithm of family head

INS = Health Insurance $($ ya $=1)$

$A \quad=$ Age of family Head

$\ln S \quad=$ Natural Logarithm of household expenses for smoking

$\ln E x=$ Natural Logarithm of expenses for household exercises

After estimating parameter and standard error, we checked model by using coefficient determination $\left(\mathrm{R}^{2}\right)$ based on $\mathrm{F}$ test. The statistical hypotheses tested were:

$$
\boldsymbol{H}_{0}: \beta_{11}=\beta_{12}=\beta_{13}=\beta_{14}=\beta_{15}=0
$$$$
\boldsymbol{H}_{1} \text { : at least comprises one } \beta_{\mathrm{i}} \neq 0
$$

If $\mathrm{F}_{\text {counted }}>\mathrm{F}_{\text {table: }} \alpha / 2$ or value of Sig. $<\alpha / 2$, then $\mathrm{H}_{0}$ can be rejected. If $F_{\text {counted }} \leq F_{\text {table: }} \alpha / 2$ or value of Sig. $>\alpha / 2$, then $H_{0}$ cannot be rejected. To test the effect of a certain variable, which is wage, one-tailed $t$ test was used as follows:

$$
\begin{aligned}
& \boldsymbol{H}_{0}: \beta_{\mathrm{i}} \leq 0 \\
& \boldsymbol{H}_{1}: \beta_{\mathrm{i}}>0
\end{aligned}
$$

Decision criteria were based on the value of $t$ counted and that of the t table with certain $d f$ as described as follows:

If $t_{\text {counted }}>t_{\text {table: }} \alpha / 2$ or value of Sig. $<\alpha / 2, H_{0}$ can be 
rejected, wage statistically does affect.

If $t_{\text {counted }} \leq t_{\text {table: }} \alpha / 2$ or value of Sig. $>\alpha / 2$ then $H_{0}$ cannot be rejected, wage does not affect significantly statistically.

This study did not absolutely adapt the model elaborated in the conceptual framework. This is because education was considered as data-scale variable with seven levels. To understand effect of education in health demand $(H)$, Chow test was used for each estimation model. Thus, equation for health demand was presented below.

$$
\begin{gathered}
\ln H=\alpha_{1}+\alpha_{2} D_{j k}+\beta_{1} \ln W+\beta_{2} A+\beta_{3} \ln S+\beta_{4} \ln E x \\
+u
\end{gathered}
$$

The above equation has determined the assumption of effect of health insurance on health demand for certain level of education which is recognized through mean deviation and marked by how big the value of interception as shown below:

1. Mean of household health demand without health insurance $\left(D_{\mathrm{jk}}=0\right)$

$$
E\left(H \backslash D_{j k}=0, X_{i}\right)=\alpha_{1}+\beta_{i} \sum_{i=1}^{4} X_{i}
$$

2. Mean of household health demand with health insurance $\left(\mathrm{D}_{\mathrm{jk}}=1\right)$

$$
E\left(H \backslash D_{j k}=1, X_{i}\right)=\left(\alpha_{1}+\alpha_{2}\right)+\beta_{i} \sum_{i=1}^{4} X_{i}
$$

In order to understand the effect of education on health demand model, Chow test was used as follows:

$$
F=\frac{\left(R S S_{r}-R S S_{U r}\right) / k}{\left(R S S_{U r}\right) / \sum_{i=1}^{7} n_{i}-7 k}
$$

$\mathrm{RSS}_{\mathrm{r}}$ means restricted residual sum of squares which refers to RSS for all sampled households without taking into account education level.

$k$, is degree of freedom $(d f)$, nominator is number of parameters estimated $\left(\alpha_{1}, \alpha_{2}, \beta_{1}, \beta_{2}, \beta_{3}, \beta_{4}\right)=6$

$\mathrm{RSS}_{\mathrm{Ur}}$ refers to unrestricted residual sum of squares which refers to number of RSS of each sampled household education level, $R S S_{U r}=\sum_{i=1}^{7} R S S_{i}$.

$\sum_{i=1}^{7} n_{i}-7 k$ refers to $d f$ denominator which means difference between number of sampled households and multiplication of number of education level with $d f$ nominator.

When education level plays some roles in health demand model, Chow test result indicated value of $F_{\text {counted }}>F_{\text {table }}$. By referring to the hypothesis, it was clear that the structure of demand model was not different at all education level and, thus, the hypothesis testing was done in the following way.

$$
\begin{aligned}
& \mathbf{H}_{0}: \mathbf{H}_{\mathrm{TPS}}=\mathbf{H}_{\mathrm{TTSD}}=\mathbf{H}_{\mathrm{SD}}=\mathbf{H}_{\mathrm{SLTP}}=\mathbf{H}_{\mathrm{SLTA}}=\mathbf{H}_{\mathrm{Dipl}}=\mathbf{H}_{\geq \mathrm{S} 1} \\
& \mathbf{H}_{1}: \mathbf{H}_{\mathrm{TPS}} \neq \mathbf{H}_{\mathrm{TTSD}} \neq \mathbf{H}_{\mathrm{SD}} \neq \mathbf{H}_{\mathrm{SLTP}} \neq \mathbf{H}_{\mathrm{SLTA}} \neq \mathbf{H}_{\mathrm{Dipl}} \neq \mathbf{H}_{\geq \mathrm{S} 1}
\end{aligned}
$$

The criterium for such testing was that if $F_{\text {counted }}>F_{\text {table }}$, null hypothesis $\left(\boldsymbol{H}_{0}\right)$ which states that demand model is not different at all education level can be rejected and is then concluded demand model at all level of education is different.

\section{Finding and Discussion}

Model of health demand was based on direct measurement using sick day. Summary of data analysis on estimation model for urban area was displayed in Table 1. 
Table 1. Summary of Health Demand Model in Urban Area: Measurement of Sick Day

\begin{tabular}{|c|c|c|c|c|c|c|c|}
\hline \multirow{2}{*}{ Variable } & \multicolumn{7}{|c|}{ Level of Education } \\
\hline & TPS & TTSD & SD & SLTP & SLTA & D1_D3 & $\geq \mathbf{S 1}$ \\
\hline$N$ & 384 & 1208 & 1678 & 982 & 1788 & 158 & 444 \\
\hline Constant & 1.56 & 1.969 & 1.782 & 1.866 & 1.391 & 1.326 & 1.719 \\
\hline$t_{-}$Constant & 4.418 & 10.495 & 11.009 & 9.601 & 8.897 & 2.751 & 4.022 \\
\hline Wage & -0.007 & $-0.014^{*}$ & $-0.018 * *$ & -0.013 & -0.01 & -0.004 & -0.024 \\
\hline t_wage & -0.716 & -1.868 & -2.538 & -1.543 & -1.458 & -0.181 & -1.154 \\
\hline Health Insurance & 0.041 & -0.081 & $0.089^{*}$ & -0.091 & 0.048 & -0.211 & 0.048 \\
\hline t_health insurance & 0.408 & -1.436 & 1.909 & -1.469 & 1.041 & -1.22 & 0.459 \\
\hline Age & 0.006 & 0.003 & $0.004^{* *}$ & $0.008 * * *$ & $0.009 * * *$ & $0.012 * *$ & 0.003 \\
\hline t_age & 1.418 & 1.361 & 2.024 & 3.677 & 4.562 & 2.399 & 0.726 \\
\hline Smoking & 0.006 & $0.02 * * *$ & 0.005 & -0.099 & 0.005 & 0.001 & 0.006 \\
\hline t_cigarette & 0.616 & 3.247 & 1.089 & -1.404 & 1.076 & 0.059 & 0.673 \\
\hline Exercise & -0.02 & -0.012 & 0.008 & -0.015 & 0.001 & -0.002 & -0.017 \\
\hline t_exercises & -0.984 & -1.087 & 1.041 & -1.646 & 0.205 & -0.136 & -1.824 \\
\hline $\mathrm{R}^{2}$ & 0.013 & 0.013 & 0.010 & 0.030 & 0.013 & 0.053 & 0.016 \\
\hline F & 1.020 & $3.286^{* *}$ & $3.246^{* *}$ & $6.019 * * *$ & $4.713 * * *$ & $1.693^{*}$ & 1.412 \\
\hline DW & 1.979 & 1.972 & 1.992 & 1.966 & 1.991 & 1.871 & 2.076 \\
\hline
\end{tabular}

Remarks:

TPS $=$ Never attended school, $*=$ Significant at level of $90 \%$

$T T S D=$ Not completed Elementary School, **= Significant at level of $95 \%$

$S D=$ Elementary School, $* * *=$ Significant at level of $99 \%$

$S L T P=$ Secondary School

$S L T A=$ High School

D1_D3 = Associate's Degree

$S 1=$ Bachelor's Degree

This demand model described health demand style in urban area for household groups with low education level - those who did not finish elementary school (TTSD) and finish elementary school $(S D)$. Wage elasticity found was relatively small (-0.018), which indicated low elasticity of health demand on wage. One percent of wage increase from a gained wage of household during the survey had not yet been able to trigger health improvement. This means that the people need an increase of wage to minimize one percent of sick day.

Relatively small wage elasticity (0.014 and 0.018) denoted weak wage influence. Nonetheless, relatively bigger wage elasticity at elementary school education level education compared to households with education lower than elementary school (TTSD) indicated an impact of education on health demand. By using Chow test, the testing of health demand model on the bases of education level indicated that health demand with sick day total was different in view of education level of head of household. Studies that support this empirically were Shehzad [24] and Gupta \& Grave [36].

Consistency of wage impact was proven through health time measurement as health stock which became health demand standard. Wage positively affected all education levels as shown in Table 2. This finding has strengthened role the of wage on health demand at an empirical result Grossman [26]; Wagstaff [23]; Gerdtham \& Johannesson [19]; Vork [21]; Shehzad [24]; Zhao [22]; Pandey [25]. 
Table 2. Summary of Health Demand Model in Urban Area: Measurement Health Time

\begin{tabular}{|c|c|c|c|c|c|c|c|}
\hline \multirow{2}{*}{ Variable } & \multicolumn{7}{|c|}{ Level of Education } \\
\hline & TPS & TTSD & SD & SLTP & SLTA & D1_D3 & $\geq \mathbf{S} 1$ \\
\hline$N$ & 569 & 1741 & 2395 & 1485 & 2702 & 275 & 728 \\
\hline Constant & 7.914 & 7.904 & 7.835 & 7.924 & 7.829 & 7.947 & 7.887 \\
\hline$t_{-}$Constant & 123.33 & 216.971 & 239.447 & 200.924 & 259.013 & 80.136 & 91.077 \\
\hline Wage & $0.006 * * *$ & $0.004 * * *$ & $0.007 * * *$ & $0.006^{* * *}$ & $0.01 * * *$ & $0.01 * *$ & $0.017 * * *$ \\
\hline t_wage & 3.027 & 3.16 & 4.96 & 3.488 & 7.492 & 2.486 & 4.334 \\
\hline $\begin{array}{c}\text { Health } \\
\text { Insurance }\end{array}$ & -0.006 & 0.012 & 0.006 & $-0.036^{* * *}$ & -0.015 & -0.045 & -0.04 \\
\hline t_insurance & -0.342 & 1.081 & 0.592 & -2.909 & -1.604 & -1.271 & -1.804 \\
\hline Age & 0.0002 & -0.0002 & $0.001 * *$ & 0.001 & $0.002 * * *$ & 0.001 & 0.0004 \\
\hline t_age & 0.257 & -0.383 & 2.376 & 1.95 & 5.217 & 0.916 & 0.531 \\
\hline Smoking & 0.003 & $0.004 * * *$ & $0.005^{* * *}$ & $0.008 * * *$ & $0.006^{* * *}$ & 0.004 & $0.003^{* *}$ \\
\hline$t \_$cigarette & 1.487 & 3.447 & 4.693 & 4.774 & 6.556 & 1.47 & 2.017 \\
\hline Exercises & 0.003 & $0.004^{* *}$ & 0.003 & 0.003 & $0.006^{* * *}$ & 0.002 & 0.002 \\
\hline t_exercises & 0.735 & 2.226 & 1.759 & 1.463 & 3.05 & 0.56 & 1.152 \\
\hline $\mathrm{R}^{2}$ & 0.035 & 0.023 & 0.027 & 0.039 & 0.055 & 0.045 & 0.043 \\
\hline $\mathrm{F}$ & $4.045^{* *}$ & $8.204 * *$ & $13.078 * * *$ & $11.981 * * *$ & $33.830 * * * *$ & $2.526^{* *}$ & $6.533^{* *}$ \\
\hline DW & 1.759 & 1.659 & 1.731 & 1.644 & 1.569 & 1.403 & 1.538 \\
\hline
\end{tabular}

Remarks:

TPS $=$ Never attended school, $*=$ Significant at level of $90 \%$

$T T S D=$ Not completed Elementary School, $* *=$ Significant at level of $95 \%$

$S D=$ Elementary School, $* * *=$ Significant at level of $99 \%$

$S L T P=$ Secondary School

$S L T A=$ High School

D1_D3 = Associate's Degree

$S 1$ = Bachelor's Degree

Having met the significance at all education levels in the measurement of health time, this model could then represent wage role in health demand. Elasticity coefficient of wage on health time was greater at high education level, which highlighted the role of education. Coefficient of 0.017 marking a change of one percent received wage when surveyed was not strong enough to change health time. In order to increase one percent of household health time when surveyed, a wage increase of one-fold of the wage received by household was needed. This finding was consistent with the role of wage at health demand according to the empirical finding of Grossman [26]; Wagstaff [23]; Gerdtham \& Johannesson [19]; Vork [21]; Shehzad [24]; Zhao [22]; Pandey [25].

Doubling the wage to one level higher was possible for the household with relatively low income. This could be done in a certain period of time when the number of working people in the household increased or got a better job. Unlikely, this did not work for the household with relatively high income since beginning, in that increase of income tended to be difficult or relatively took time.

Inelastic health demand within a long time brought some implications for health price increase which further caused medical care price to be out of pocket $[37,38]$. This could potentially create disparity of people's health stock [39, 40]. To avoid such an implication, health funding in the form of health insurance was needed to guarantee all the people [41, 42].

\section{Conclusions}

In conclusion, wage increase partly decreases sick day. The increase of health demand because of an increase in wage is limited among household groups with low education level. Based on health time measurement, not only does increase of wage trigger an increase of health demand for all household groups, but it also pushes households to be able to buy better consumption, which ultimately can increase health time. The greater wage elasticity is at high education level indicates increase of wage and better formal education that encourages health demand.

The increase of wage promotes another effect for health demand - that is encouraging the ability to use health insurance. Higher wage level enables households to be involved in health insurance because they can pay for it. Even though wage has been able to increase ability to own 
health insurance, aging effect toward health demand is greater through increase of health depreciation. This is because increase in age has encouraged an increase of sick day total. One important consideration to be taken up is that health depreciation through age grouping in the estimation model is expected to ensure accurate health demand estimation.

\section{REFERENCES}

[1] Mills A., S. Bannet, L. Gilson.. "Health, economic development, and household poverty: The role of the health sector.” In Bennett S., Gilson L., Mills A. (Eds), Health, Economic Development and Household Poverty: From understanding to action, New York: Rudtledge, 2008, pp. 21-38.

[2] Alsen M., Bloom D., Canning D., Jamison, D., "The consequences of population health for economic performance.” In Bennett S., Gilson L., Mills A. (Eds), Health, Economic Development and Household Poverty: From understanding to action, New York: Rudtledge, 2008, pp. 41-59.

[3] Rosen S., Simon J., Fox M., "Illness and labor productivity: A case study from rural Kenya." Bennett S., Gilson L., Mills A. (Eds), Health, Economic Development and Household Poverty: From understanding to action, New York: Rudtledge, 2008, pp. 40-57.

[4] Nasirin C., Lionardo A., "Decentralization, Public Services and Neglected Children in Mataram City, West Nusa Tenggara," Research Horizon, vol. 1, no. 2, pp. 55-61, 2021.

[5] Edwards R. T., "Paradigms and research programmes: is it time to move from health care economics to health economics?," Health Economics, vol. 10, no. 7, 635-649, 2001.

[6] Meliyanni J., "The impact of the Indonesian health card program: a matching estimator approach," Journal of health economics, vol. 28, no. 1, pp. 35-53, 2009.

[7] Becker, Gery S.1965. "A Theory of the Allocation of Time." Economic, Vol. 75, no. 299, pp. 493-517.

[8] Grossman M., "The demand for health: A theoretical and empirical investigation," New York: Columbus University Press, 1972b.

[9] Cullis J. G, West P. A., "The Economics of Health, An Introduction," New York: New York University Press, 1979.

[10] McGuire A., Handerson J., Mooney G., "The Economics of Health Care: An Introductory text," London \& New York: Routledge \& Kagan Paul Ltd., 1998.

[11] Zweifel P., Breyer F., Kifman M., "Health Economics,” 2nd ed., London-New York: Springer, 2009.

[12] Leibowitz A., "The demand for health and health concerns after 30 years," Journal of Health Economics, vol. 23, no. 4, pp. 663-71, 2004.
[13] Wagstaff A., "The demand for health: theory and application," Epidemiological and Community Health, vol. 40, no. 1, pp. 1-11, 1986.

[14] Grossman M., "The Human Capital Model of the Demand for Health," Working Paper No. 7078. Cambridge, MA: National Bureau of Economic Research, 1999.

[15] Abdul-Rahman M. F, "The Demand for Physical Activity an Application of Grossman's Health Demand Model to Elderly Population," Ph.D Dissertation, School of the Ohio State University, 2008. http://rave.ohiolink.edu/etdc/view? acc_num=osu1199127215.

[16] Rexford E., Stephen N. P., "Health Economics: Theories, Insights, and Industry Studies.," Thomson/South-Western, Mason, Ohio, 2004.

[17] Geda A., Simeles A., "Demand for health in Ethiopia: exploratory analysis from welfare monitoring surveys," Paper presented at the African Economic Conference 2009, Addis Ababa 11-13 November 2009.

[18] Khanam R., Nghiem H.S., Connelly L.B., "Child health and the income gradient: Evidence from Australia," Journal of Health Economics, vol. 28, no. 4, pp. 805-817, 2009.

[19] Gerdtham U. G., Johannesson M., "New estimates of the demand for health: Results based on a categorical health measure and Swedish micro data," Journal of Social Science and Medicine, vol. 49, no. 10, pp. 1325-1332, 1997.

[20] Gerdtham U. G., Johannesson M., Lundberg L., Isacson D., "The demand for health: results from new measures of health capital," European Journal of Political Economy, vol. 15 , no. 3, pp. 501-521, 1999.

[21] Vork A., "An empirical estimation of the Grossman health demand model using Estonian survey data," Term Paper in doctoral course in health economics, Department of Economics, University of Bergen, 2000.

[22] Zhao Z., "Health Demand and Health Determinant in China," Discussion Paper Series. IZA DP No.4098, 2007.

[23] Wagstaff A, "The demand for health: an empirical reformulation of the Grossman model," Health Economics, vol. 2, no. 2, pp. 189-98, 1993.

[24] Shehzad S., "The determinants of child health in Pakistan: An economic analysis," Social Indicators Research,vol. 78, no. 3 pp. 531-556, 2006.

[25] Pandey M. K., “Association between Marital Status and Health: Examining the Role of Age and Gender," ASARC Working Paper, 2009.

[26] Grossman M., "On the Concept of Health Capital and the Demand for Health," Journal of Political Economy, vol. 80, no. 2, pp. 223-255, 1972a.

[27] Nocera S. Zweifel P., "The demand for health: an empirical test of the Grossman model using panel data," In Zweifel P. (Ed.), Health, the medical profession and regulation, Boston/Dordrecht/London: Kluwer academic publishers, 1998, pp. 35-49.

[28] Mocan H. N., Tekin E., Zax, J. S., “The Demand for Medical Care in Urban China," World Development, vol. 32, no. 2, pp. 209-304, 2004. 
[29] Grossman M., "On optimal length of life," Journal of Health Economics, vol. 17, no. pp. 495-509, 1998.

[30] Grossman M., "The relationship between health and schooling," Eastern Economic Journal, vol. 34, pp. 281-292, 2008.

[31] Aranda L. G., "Health Economics, Compression of Morbidity, and the Grossman Model," Ph.D Dissertation, Universita Ca'Foscari Venezia, 2010.

[32] Jacobson L., "The family as producer of health - an extended Grossman model," Journal of Health Economics, vol. 19 , no. 5, pp. 611-637, 2000.

[33] Bolin K., Jacobson L., Lindgren B., "The family as the health producer when spouse are Nash-bargainers," Health Economics, vol. 20, no. 3, pp. 349-362, 2001.

[34] Hjortsberg C., "Determinants of household health care expenditure-the case of Zambia," Lund University, Center for Health Economics (LUCHE), 2003.

[35] Ichwan M., "Health Demand in Indonesia: Empirical Study at Indonesia's Household Which Suffer the Health Problem," Doctoral Dissertation, Universitas Diponegoro, Semarang, Indonesia, 2013.

[36] Gupta N. D., Grave J., "Overweight and Obesity and the Demand for Primary Physician Care," Discussion Paper Series. IZA DP. No. 4098, 2009.
[37] Otobideh S.A., Moeeni S., Mohammadzadeh Y., Rahimi B., Shabaninejad H., Yusefzadeh, H., "Estimation of the income and price elasticity of pharmaceutical import demand in Iran," International Journal of Pharmaceutical and Healthcare Marketing, Vol. ahead-of-print No. ahead-of-print, 2021.https://doi.org/10.1108/IJPHM-05-20 20-0045

[38] Pendzialek J. B., Simic D., Stock S., "Differences in price elasticities of demand for health insurance: a systematic review," The European Journal of Health Economics, vol. 17, no. 1, pp. 5-21, 2016.

[39] Grossman M., "The demand for health," Columbia University Press, 2017.

[40] Ellis, R. P., Martins, B., \& Zhu, W. (2017). Health care demand elasticities by type of service. Journal of health economics, 55, 232-243.

[41] Turski I., Mashika H., Tkachenko T., Khmara M., Komarnitskyi I., Oliinyk M., "Medical Tourism: Analysis of the State of International Tourism and Prospects for Domestic Development," Universal Journal of Public Health, vol. 9, no. 2, pp. 27-34, 2021. DOI: 10.13189/ujph.2021.090201.

[42] Ozyigit A., "The Impact of Years of Schooling on Dementia: Panel Data Evidence from Europe," Universal Journal of Public Health, vol. 9, no. 1, pp. 18-25, 2021. DOI: 10.13189/ujph.2021.090102. 